Portland State University

PDXScholar

7-25-1995

\title{
Behavioral Differences in the Classroom: U.S. University Teachers and Chinese University Teachers
}

Xiaocheih Sun

Portland State University

Follow this and additional works at: https://pdxscholar.library.pdx.edu/open_access_etds

Part of the Speech and Rhetorical Studies Commons

Let us know how access to this document benefits you.

\section{Recommended Citation}

Sun, Xiaocheih, "Behavioral Differences in the Classroom: U.S. University Teachers and Chinese University Teachers" (1995). Dissertations and Theses. Paper 4921.

https://doi.org/10.15760/etd.6797

This Thesis is brought to you for free and open access. It has been accepted for inclusion in Dissertations and Theses by an authorized administrator of PDXScholar. Please contact us if we can make this document more accessible: pdxscholar@pdx.edu. 


\section{THESIS APPROVAL}

The abstract and thesis of Xiaocheih Sun for the Master of Arts in Speech Communication were presented July 25, 1995, and accepted by the thesis committee and the department.

\section{COMMITTEE APPROVALS:}
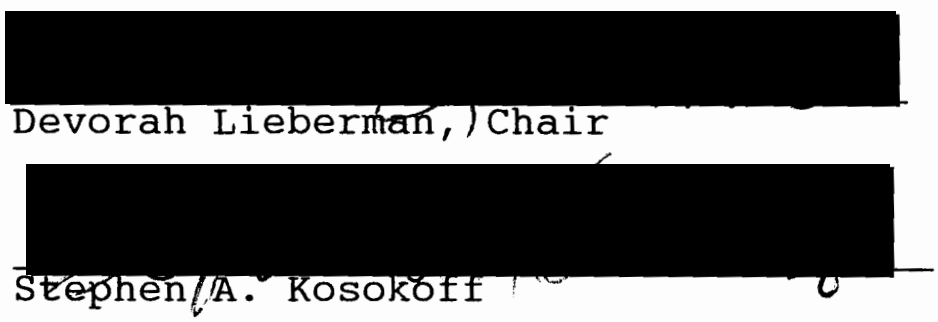

\section{Kimberley Brown \\ Representative of the office of Graduate Studies}

DEPARTMENT APPROVAL:

Stephep A. Kosokott, Chair

Department of Speech Communication

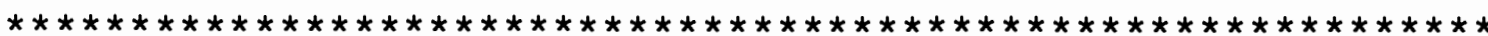

ACCEPTED FOR PORTLAND STATE UNIVERSITY BY THE LIBRARY by on

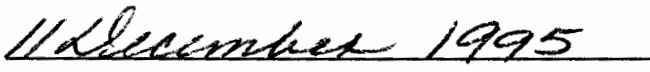




\section{ABSTRACT}

An abstract of the thesis of Xiaocheih Sun for the Master of Arts in Speech Communication presented July 25, 1995.

Title: Behavioral Differences In The Classroom: U.S. University Teachers And Chinese University Teachers.

Although intercultural scholars examine the differences in cultural values, beliefs, and attitudes between the U.S. and China, few specifically have studied cultural differences between U.S. and Chinese university classrooms. This study examines behavioral differences exhibited by U.S. teachers in U.S. university classrooms and Chinese teachers in Chinese university classrooms.

This research addresses three areas of significance. First, Chinese students studying in the U.S. who read this thesis may be better able to cope with the U.S. educational system and communicate more effectively with both U.S. students and teachers. Second, this research may help U.S. university teachers to better understand the chinese culture and Chinese students. Third, this research may increase U.S. teachers' awareness of and sensitivity to the increasingly multicultural classroom environment in the U.S. Three male university teachers in the U.S. and three male university teachers in China were observed and videotaped in this study. The data analysis was guided by 
categories establish by Gudykunst (1988), Hofstede (1986), and Lieberman (1993) as behavioral indicators of cultural styles.

Several interesting findings occurred among overall descriptive observation and qualitative accounts of observations. First, a powerful trend of behavioral differences exhibited in the classroom by U.S. university teachers and Chinese university teachers was found. The findings in this search strongly support findings by Gudykunst (1988), Hofstede (1986), and Lieberman (1993) that U.S. university teachers exhibited far more individualist/direct communication styles and small power distance/personal communication styles than Chinese teachers, while Chinese teachers exhibited more collectivist/indirect communication styles and large power distance/contextual communication styles than U.S. teachers. Second, the results of this research provide valuable insights for both U.S. university teachers and Chinese university teachers; that is, culture reflects teachers' and students' values, assumptions, and behaviors. U.S. culture reflects values, assumptions, and behaviors, such as individualism, direct communication styles, small power distance, and personal communication styles. However, Chinese culture reflects collectivism, indirect communication styles, large power distance, and contextual communication styles. 
BEHAVIORAL DIFFERENCES IN THE CLASSROOM: U.S. UNIVERSITY TEACHERS AND CHINESE UNIVERSITY TEACHERS

by

XIAOCHEIH SUN

A thesis submitted in partial fulfillment of the requirements for the degree of

\author{
MASTER OF ARTS \\ in \\ SPEECH COMMUNICATION
}

Portland State University

1995 


\section{ACKNOWLEDGEMENTS}

I would like to take this opportunity to express my appreciation to those people who offered their assistance to me throughout my experience as a graduate student. For their advice and help during the completion of this thesis, I am grateful to my thesis committee members Dr. Lieberman, Dr. Kosokoff, and Dr. Brown. Specifically, I would like to thank Dr. Lieberman, an unusual, understandable professor. Without your relentless help, continuous encouragement, academic advice, and hard work, the completion of the thesis would have been impossible.

I would like to express my heartfelt thanks to my friend and husband Joe Hsiao, for your love, understanding, and support during my whole graduate education. Without you, I would not have been able to complete this at all. Words would not be enough to express how much I appreciate your love and support.

Thanks to my former professor, Dr. Sermol, for being very nice to me when I started to study this major at Portland State University and for your continuous encouragement to me when I had difficult times. Thanks to Rosalind Wang, who was my first friend and adviser in the U.S., helped me to come to the U.S. and walked me through the culture shock. I respect you forever. Thanks to my 
dearest friends, Michelle Ruff, Vivian Hsiao, and Rui Chen. Your friendship and support has meant a lot to me. I will always cherish our friendship. Thanks to all my friends and my relatives. You are always in my mind. A very special thank you goes to three young English teachers, Sean Cowne, Thomas Gustav and Bennett Huffman of Portland State University. You allowed me to video-tape your classes, and cooperated with me all the time.

Finally, I would like to thank my beloved parents in China, Zhaogi sun and Zhaoxiu Shen, for your love, encouragement and unending support. Without you, I would not have achieved my dreams. Especially I would like to thank my sister and brother, Huan Sun and Liang Sun, who helped me to video-tape and selected classes in China. Without you, I would never have completed my thesis. So, in gratitude and love, I dedicate this thesis to my family. I love you and miss you all! 
TABLE OF CONTENTS

PAGE

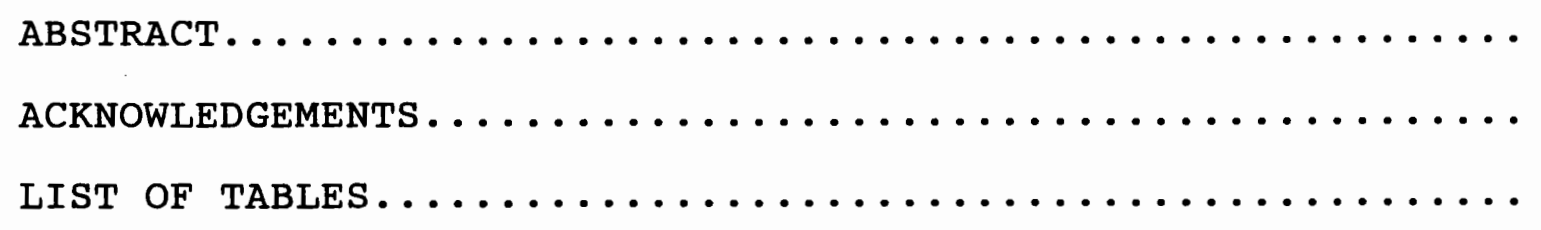

CHAPTER

I. INTRODUCTION 1

Significance and justification 4

Research questions 5

II. REVIEW OF THE LITERATURE 6

$\begin{array}{ll}\text { Definitions } & 24\end{array}$

III. METHODS AND PROCEDURES 25

Overview 25

Strengths of the study 25

$\begin{array}{ll}\text { Limitations of the study } & 26\end{array}$

$\begin{array}{ll}\text { Subjects } & 26\end{array}$

$\begin{array}{ll}\text { Procedures } & 27\end{array}$

$\begin{array}{ll}\text { Analysis } & 29\end{array}$

The power of video 32

Training the research assistant 33

Intercoder reliability 33 
IV. RESULTS 35

Overall descriptive observation 36

Qualitative accounts of observations $\quad 40$

$\begin{array}{ll}\text { V. DISCUSSION } & 45\end{array}$

Results of research questions 46

Limitations $\quad 57$

Recommendations for future study 58

$\begin{array}{ll}\text { Conclusion } & 60\end{array}$

$\begin{array}{lll}\text { VI. REFERENCES } & 61\end{array}$

$\begin{array}{lll}\text { VII. APPENDIX } & 65\end{array}$

A: Informed consent form for teachers and $\begin{array}{ll}\text { students } & 65\end{array}$

B : Matrix $\quad 70$

C: Behavioral indicators of cultural styles (Hofstede, Gudykunst and Lieberman) 71

D: Transcripts 72 


\section{LIST OF TABLES}

TABLES

PAGE

I Individual observation of Chinese Teachers Behaviors by Individualist/Collectivism and

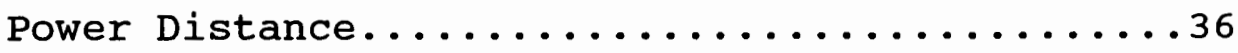

II Individual Observation of U.S. Teachers Behaviors by Individualist/Collectivism and

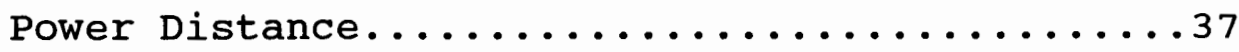

III Total observation of Chinese and U.S. Teachers Behaviors by Individualist/Collectivism and

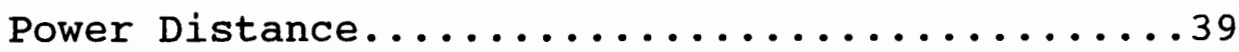


CHAPTER I

\section{INTRODUCTION}

Following China's open-door policy in the late $1970 \mathrm{~s}$ and early 1980s, the number of Chinese students in the United States increased dramatically each year. According to official U.S. figures, there were 2,770 Chinese students studying in U.S. universities during the 1980-1981 school year (Thomas, 1992), while at the end of 1993, there were 45,130 Chinese students enrolled in universities in the United States (Zikopoulos, 1991). Thus, within a 10 year period, the number of Chinese students in the U.S. increased by over 43,000 .

A land abundant with people, China does not have enough "employment opportunity" to go around. Since the late 1970s, slowly, painstakingly, opportunity has on occasion come to this country. Kenneth Starck (1991) states, "open markets have helped create opportunities for many people, especially in the rural areas. An open-door policy toward other nations, including joint business ventures, has spawned additional opportunities" (p.117). However, better job opportunities need education, and the sector of Chinese society that suffers most is education (Austin \& Zhang, 
1987). Although the number of universities and colleges in China have increased fourfold in recent years, according to Austin \& Zhang, studying abroad is a dream for many Chinese students. Most Chinese students believe that a universitylevel degree in a U.S. university will create opportunities and "rescue them from a job market that is oversupplied, heavily bureaucratized, unchallenging, and often unrewarding" (Starck, 1991, p.117). However, most universities in China can not satisfy students' needs, and they do not offer courses about differences between American culture and Chinese cultures. Many Chinese students do not have knowledge about U.S. culture before they came to the United states, and they do not think about intercultural communication skills needed in the United States (Liu, 1984)

Several scholars have said that culture is the foundation of communication (Samovar and Porter, 1988; Hall, 1989). When people speak, they are obviously communicating, but when they smile, wave, walk, or gesture, they are also communicating. Samovar and Porter write, "our behaviors become messages to which other people may respond" (p.7). According to Samovar and Porter, communication may be defined as, "that which happens whenever someone responds to the behavior or the residue of the behavior of another person" (p.7). But what people talk about, how they talk, what they think, and how they think are influenced by 
their culture. In turn, all of this helps shape, define, and perpetuate the culture. Culture cannot exist without communication and vice versa (Samovar and Porter, 1991, p.21) .

since no two cultures are alike, what and/or how students are taught in their culture may be different from what and/or how others are taught in other cultures. People are not usually aware of their own cultural values, beliefs and attitudes until they encounter people whose upbringing has prepared them differently from their own. When persons from different cultural backgrounds interact with teachers and students in the classroom, basic cultural differences often emerge. Incongruent expectations and misunderstandings may arise between teachers and students, and may lead to conflict. These conflicts occur, partly because individuals from different cultures often have different expectations and interpretations of the same behavior (Albert \& Adamopoulos, 1976; Albert \& Triandis, 1979). Cultural differences affect the interaction process and possibly decrease intercultural communication effectiveness (Samover and Porter, 1988, p.17). Crosscultural studies of two cultures offer information which can aid intercultural interaction.

Hu (1991), Liang (1991), and Pia (1989) describe the differences in cultural values, beliefs, and attitudes between the U.S. and China. Hu (1991) points out 
differences between Chinese and Americans in values, beliefs and attitudes, and offers suggestions to U.S. individuals on how to interact effectively with Chinese. Liang (1991) mentions the differences in communication styles between Americans and Chinese. Pia (1989) compares the learning style differences between Chinese students and American students. However, few scholars ( $H u, 1991 ; \mathrm{Zhu}, 1991$ ) have studied teachers' behavioral differences between the U.S. and China in university classroom. For example, zhu (1991) mentions that there are such great differences between the ways in which instruction is presented in U.S. and in Chinese university classrooms, suggesting that there needs to be increased understanding of these cultural differences, particularly when a chinese teacher is teaching in the U.S. However, she does not address which particular behavioral differences occur in university classrooms in the U.S. and China. This study examines potential behavioral differences and similarities exhibited by U.S. teachers in the U.S. university classroom and Chinese teachers in the Chinese university classroom.

\section{SIGNIFICANCE AND JUSTIFICATION}

There will be three areas of potential significance for this research. First, Chinese students who read this thesis may be better able to cope with the U.S. educational system and communicate more effectively with both U.S. students and 
teachers. Second, this research may help U.S. teachers to better understand the Chinese culture and Chinese students. Third, this research may increase U.S. teachers' awareness of and sensitivity to the increasingly multicultural classroom environment in the U.S.

\section{RESEARCH QUESTIONS}

Based upon the review of literature and Hofstede's twodimensional model of cultural differences on a behavioral continuum (1986): individualism and collectivism, small power distance and large power distance, and Gudykunst's two verbal communication styles (1988): direct and indirect style, personal and contextual style, the following questions are asked:

1. What behaviors do U.S. and Chinese university teachers exhibit that reflect Hofstede's concept of "individualism" and Gudykunst's direct communication style?

2. What behaviors do U.S. and Chinese university teachers exhibit that reflect Hofstede's concept of "collectivism" and Gudykunst's indirect communication style?

3. What behaviors do U.S. and Chinese university teachers exhibit that reflect Hofstede's concept of "small power distance" and Gudykunst's personal communication style? 4. What behaviors do U.S. and Chinese university teachers exhibit that reflect Hofstede's concept of "large power distance" and Gudykunst's contextual communication style? 


\section{CHAPTER II}

\section{REVIEW OF THE LITERATURE}

As people grow up, they learn certain values and assumptions from their parents, relatives, teachers, books, newspapers, and television programs. Values, according to Clyde Kluckhohn, (Condon \& Yousef, 1987, p.51) are ideas about what is good and bad, right and wrong, desirable and undesirable, normal and abnormal, proper and improper. Assumptions (Stewart \& Bennett, 1991) are the postulates about people, life, and the way things are. People who grow up in a particular culture share many values and assumptions. That does not mean people all share exactly the same values to exactly the same extent; it does mean that most of them, most of the time, agree with each others' ideas about what is good and bad, right and wrong, desirable and undesirable, normal and abnormal, proper and improper. Also they tend to agree with each other's assumptions about values such a human nature and social relationships (Condon \& Yousef, 1987). For example, people raised in the U.S. tend to assume that education requires learners to question and challenge the older "expert" when the expert's ideas 
disagree with the learners' (Althen, 1988). In China, people assume that education takes place most efficiently when respectful young people absorb all they can of what older, wiser people already know. The young people tend not to challenge nor to discuss what they are taught (Liu, $1984)$.

U.S. culture tends to reflect values, such as individualism, privacy, equality, informality, the future, change and progress, goodness of humanity, achievement, action, work, materialism, directness, and assertiveness (Althen, 1988; Condon \& Yousef, 1987; Kluckhohn, 1948; Stewart \& Bennett, 1991). Traditionally, the term "individualism" has been used to refer to the "feeling or conduct in which the guiding principle is the interest of the individual" (Webster's Dictionary, 2nd edition, p.688). Waterman (1984) contends that individualism is embodied in four psychological qualities: a sense of personal identity (Erikson), self-actualization (Maslow), internal locus of control (Rotter), and post-conventional principled moral reasoning (Kohlberg). Individualism is one of the basic values in the U.S. society. Bellah, Madsen, Sullivan, Swidler, and Tipton (1985) agree that individualism lies at the very core of American culture, contending that "individualism... has marched inexorably through our history" (p.vii). Americans have been "trained since very early in their lives to consider themselves as separate individuals 
who are responsible for their own situations in life and their own destinies" (Althen, 1988, P.4).

However, Chinese values tend to be grounded in collectivism, inequality, intragroup harmony and avoidance of overt conflict in interpersonal relations (Ho, 1979; $\mathrm{Hu}$, 1991; Hui, 1981; Singh, Huang \& Thompson. 1962). Collectivism, according to Hui (1986), can be summarized by the word "concern," which refers to bonds and links with others. The more concern one has toward others, the more bonds with others are felt and acted upon, the more collectivistic the person is.

Hofstede (1986) discusses a two-dimensional model of cultural differences: individualism vs. collectivism and small power distance vs. large power distance.

According to Hofstede, cultures encourage individualism or collectivism and these values can be plotted on a continuum. He states, "Individualist cultures assume that any person looks primarily after his/her own interest and the interest of his/her immediate family" (p.306). People are expected to take care of themselves and their immediate families and to pursue individual achievement. Collectivist cultures assume that any person belongs to one or more tight "in-groups" from which he/she cannot detach him/herself. The "in-group" protects the interest of its members, but in turn, expects their permanent loyalty. A collectivist society tends to be tightly integrated; an individualist 
society tends to be loosely integrated (Hofstede, 1986). He adds that behaviors of people in individualist culture might have a positive association with whatever is new, while behaviors of people in collectivist culture might have a more positive association with that which is rooted in tradition.

Students from collectivist cultures define themselves according to membership in groups and give the maintenance of groups a high priority. Students from individualist cultures define themselves by individual achievement. In writing of collectivism in the classroom, Hofstede (1991) states:

In the collectivist classroom the virtues of harmony and the maintenance of "face" reign supreme. Confrontations and conflicts should be avoided, or at least formulated so as not to hurt anyone; even students should not lose face if this can be avoided. (p. 62)

In contrast, students in individualist cultures frequently state points of view that are in conflict with the teacher's and/or with other students'. Hofstede (1986) goes on to say that students in individualist cultures are also not particularly concerned with losing face. According to Hofstede, power distance as a value in a culture influences the extent to which the people in a society accept the fact that power in institutions and organizations is distributed unequally among individuals. 
Small power distance characterizes a society in which people may be uncomfortable with an unequal distribution of power and thus try to bring about a more nearly equal distribution. In small-power-distance cultures, for example, teachers tend to respect the independence of their students, using student-centered education, and students are even encouraged to contradict or criticize teachers. In large power distance classrooms (Hofstede, 1986), teachers tend to merit the respect of their students, using teacher-centered education and teachers are neither contradicted nor publicly criticized (Hofstede, 1986). Hofstede's correlational data in large power distance countries suggests that:

Teachers are treated with respect (older teachers even more than younger ones); students may have to stand up when they enter. The educational process is teachercentered; teachers outline the intellectual paths to be followed. In the classroom there is supposed to be a strict order with the teacher initiating all communication. Student in class speak up only when invited to; teachers are never publicly contradicted or criticized and are treated with deference even outside school..... In such a system the quality of one's learning is virtually exclusively dependent on the excellence of one's teachers. (p. 34, 1991).

In a word, individualist cultures encourage individual achievement; collectivist cultures define group maintenance; small power distances cultures exhibit an equal distribution and large power distances cultures accept an unequally distribution. 
Gudykunst (1988) uses Hofstede's cultural variability dimensions of individualism and collectivism, small power distance and large power distance to explain and present two verbal communication styles: direct versus indirect style, and personal versus contextual style.

Gudykunst states that "the direct verbal style refers to verbal messages that embody and invoke speakers' true intentions in terms of their wants, needs, and desires in the discourse process. The indirect verbal style, in contrast, refers to verbal messages that camouflage and conceal speakers' true intentions in terms of their wants, needs, and goals in the discourse situation" (p.101). Okabe (1983) make an observation, pointing out that:

Americans' tendency to use explicit words is the most noteworthy characteristic of their communication style. They prefer to employ such categorical words as "absolutely," "certainty," and "positively."... The English syntax dictates that the absolute "I" be placed at the beginning of a sentence in most cases, and that the subject-predicate relation be constructed in an ordinary sentence.....By contrast, the cultural

assumptions of interdependence and harmony require that Chinese and Japanese speakers limit themselves to implicit and even ambiguous use of words. In order to avoid leaving an assertive impression, they like to depend more frequently on qualifiers such as "maybe," "perhaps," "probably," and "somewhat."(p. 36)

Similar observations have been advanced by Hsu (1981) concerning the differences in communication styles between Chinese and Americans. He notes that:

...the American emphasis on self-expression not only enables the American child to feel unrestrained by the 
group, but also makes him or her confident that he or she can go beyond it. The chinese lack of emphasis on self-expression not only leads the Chinese child to develop a greater consciousness of the status quo but also serves to tone down any desire on his or her part to transcend the larger scheme of things. (p. 94)

The value orientation of individualism propels Americans to speak their minds freely through direct verbal expressions. Individualistic values foster the norms of honesty and openness. Honesty and openness are achieved through the use of precise, straightforward language behaviors. The value orientation of collectivism, in contrast, hardly speak through explicit verbal communication style, because group harmony and conformity are accomplished through the use of imprecise, ambiguous verbal communication behaviors.

Verbal personal style is individual-centered language, while verbal contextual style is role-centered language. According to Gudykunst (1988), verbal personal style refers to the use of certain linguistic devices to enhance the sense of "I" identity, and verbal contextual style refers to the use of certain linguistic signals to emphasize the sense of "role" identity. In the verbal personal style, meanings are expressed for the purpose of emphasizing "personhood," while in the verbal contextual style, meanings are expressed for the purpose of emphasizing prescribed role relationships.

Young (1982) observed and analyzed Chinese discourse 
styles. She found that rather than relying on a preview statement to orient the listener to the overall direction of the discourse, Chinese discourse relies heavily on contextual cues and tends to use single word items such as "because," "as," and "so" to replace whole clause connectives commonly used in English, such as "in view of the fact that," "to begin with," or "in conclusion" (Young, 1982, p. 79).

Okabe (1983) contends that a person-oriented language stresses informality and symmetrical power relationships, while a contextual-oriented language emphasizes formality and asymmetrical power relationships. He states:

Americans tend to treat other people with informality and directness. They shun the formal codes of conduct, titles, honorifics, and ritualistic manners in the interaction with others. They instead prefer a firstname basis and direct address. They also strive to equalize the language style between the sexes. While the Chinese are likely to assume that formality is essential in their human relations. They are apt to feel uncomfortable in some informal situations (p. 27).

The U.S. is a country of immigrants who have diverse linguistic, cultural, and philosophical background (Okabe, 1983; Yoshikawa, 1982). In this culturally diverse society with many different value systems and diverse cultural assumptions, all participants in a conversation are considered responsible for their own opinions, and it is expected that ideas are exchanged verbally (Ramsey et. al. 1983). The lack of shared assumptions may inspire the 
American speakers to verbalize their messages in order to make their intent clear (Okabe, 1984). For many Americans, the ultimate purpose of communication is pragmatic and oriented toward cause and effect and linear determinism (Ramsey et. al., 1983). Therefore, U. S. communication tends to depend on verbal expression and respect verbalizations as the tool to explain feelings and thoughts (Kato et. al, 1991). U.S. individuals depend more on spoken words than on nonverbal behavior to convey their messages (Althen, 1988).

Confucianism has endured as the basic social and political value system in China for over two thousand years and has influenced the Chinese communication style (Yum, 1988). According to Confucianism, proper human relationships are the basis of society. Confucianism sets forth principles from which right conduct arises: jen (humanism), i (faithfulness), li (propriety), and chih (wisdom or a liberal education). The Chinese people develop their affective bonds with immediate members of the family and rely on a great deal of the unspoken, the nonverbal aspects of on interaction (Liang, 1991). They tend to understand each other without verbal communication and look for meanings and interpretation of the interaction from either the physical context (i.e. time, setting), or the social psychological context (i.e. social status, relationship, gender, etc.) (Liang, 1991). Therefore, to 
the Chinese people, much of the interpretations of interactions come from the nonverbal, unspoken and indirect aspects of the message (Liang, 1991).

In the following pages, some cultural values and assumptions based on the previous discussion which influence university teacher behavioral differences in the U.S. university and Chinese university classrooms will be discussed.

Basic Differences In Chinese and U.S. University Education Systems

\section{Chinese Educational System}

Chinese culture places strong emphasis on education (Liu, 1984). The Chinese people have traditionally valued education as one of life's most worthwhile pursuits and the high priority which the Chinese have assigned to education throughout their five thousand year history remains to this day.

The education system in China follows a basic $6-3-3-4$ pattern, that is, six years elementary school, three years junior high school, three years senior high school and four years university (Mackerras, 1991). According to the current education system of universities in China, the academic year is divided into two semesters, the first beginning in early or mid-september and continuing until late January. After the winter vacation (three to four 
weeks), the second semester begins in February and goes on usually to the end of June. Summer sessions are rare.

There are over 1,000 universities, colleges and other institutes of higher learning in China. In most university departments, 128 credits taken over four years is the minimum requirement for completion of the Bachelor's degree. In general, the students' courses are heavily concentrated in their major subjects. The students enter a structured program and proceed without electives. Recently there has been a trend towards permitting greater breadth of selection, and students at several universities are being given wider choices of electives.

New students enter university straight from high school through the recently revived national examinations. only about five percent of high school students can pass the examinations to enter universities (Mackerras, 1991). Then they are tightly integrated into small groups; the principal groups for most students are their roommates and their classmates (Hu, 1991). Classmates are the students who go together as a group from class to class. Since there is relatively little choice of courses for Chinese, their academic schedules are largely determined on a group basis ( $\mathrm{Hu}, 1991)$

\section{U.S. Educational System}

The U.S. educational system is integrally related to 
the values and assumptions of the society, that is, equality, individualism, and freedom. The system is based on the idea that as many people as possible should have access to as much education as possible (Althen, 1988). It does not mean that everyone has an equal opportunity to enter Harvard, Stanford, or other highly competitive universities, because admission to such universities is generally restricted to the most academically, and financially able.

The U.S. system is likely to enroll a broader range of students than the Chinese system that seeks to educate only the few who seem especially suited for academic work (Barnes, 1984). Each student has a right to determine his or her roommates, place of residence, academic courses, academic schedule, and extracurricular activities (1992). This reflects the outcomes of individualism and equality as a value system of the U.S. society.

\section{The Meaning of "Teacher"}

\section{Chinese Teacher}

In the philosophical and cultural history of China, Confucianism, as previously mentioned, has endured as the basic social and political value system for over two thousand years (Yum, 1988). According to Confucianism, the teacher generally is viewed as a dispenser of knowledge. Wisdom comes with age and all important learning is 
"postfigurative" which means nobody can know everything when he/she is young. They have to learn things from the old people (Hu, 1991). The task of the student is to absorb knowledge. Students expect the teacher to outline paths to follow and speak up in class only when invited by the teacher (Hofstede, 1991). Teacher-centered education is encouraged and students feel comfortable in structured learning situations: precise objectives, detailed assignments, strict timetables and so on (Sung, 1979). Positive teacher/student and student/teacher interactions are built upon the traditional respect accorded the teacher in Chinese culture (Hu, 1991). The Chinese word for a teacher at any level, "laoshi", (the word "lao" in Chinese means old and wisdom) is not merely a designation of social rank and function, but a term signifying considerable respect and deference (Hu, 1991). These create the large power distances between the teachers and the students. The students try to please the teachers, who are looked upon as authority figures second only to the parents. The role of the teacher is an exalted one. Respect for the teacher as a revered authority is so ingrained that it is difficult for students to conceive of misbehavior towards the teachers (Sung, 1979).

\section{U.S. Teacher}

However, U.S. teachers do not enjoy as a high status in 
the society (Althen, 1988, p.59). They are not well paid, and their working conditions are usually less comfortable than those of workers in other white collar professions (Althen, 1988). They are not as well respected as are people who actually "do" something rather than "just" teach. The U.S. culture, according to Hofstede (1986), encourages small power distances; that is, teachers tend to respect the independence of their students, using student-centered education, and students are even encouraged to contradict or criticize teachers. In the U.S., the teacher has both the role of guiding students to find answers themselves and the role of teaching students how to ask questions. Sometimes, the teacher may answer, "I don't know" to a question the student has asked and then discuss the question with the student.

\section{The Meaning of Students}

\section{Chinese students}

In China, the awe and respect for the teachers has its pros and cons (Sung, 1979). Students tend to accept without question what teachers say, partly, due to the chinese system of education, in which learning is largely by rote, and, in part, because students do not feel that it is proper to challenge the teacher. They have reservations about asking questions in class; they exhibit shyness, not wanting to appear foolish by asking a "dumb" question, not wanting 
to waste class time on questions that maybe only one person has, and so on. But in addition to these common motives, there are also additional causes for a reluctance to ask the teacher a question. If the teacher does not know the answer, he/she might lose face ( $\mathrm{Hu}, 1991)$. Chinese are more sensitive about losing face than American (Hofstede, 1991). Furthermore, it disrupts the teacher's planning which would be considered rude. This cultural characteristic may explain why so many Chinese students are non-participative, non-assertive, and non-questioning, critical, challenging in class (Hu, 1991).

The Chinese students also find it is difficult to make a decision by themselves in class, because they are used to a passive method of learning (Van Naerseen, 1984). They learn by listening, watching, and imitating rather than by actively doing things and discovering things by themselves. They expect the teacher to initiate all activities and prefer the teacher who deals with various topics in a manner that might be called "by the numbers." They will feel uncomfortable in expressing a point of view in public. Hu (1991) in his book writes:

Besides the fact that the chinese educational tradition places no value on self-expression by students, the following more practical reasons are sometimes given by individual students for their reluctance to speak. poor students usually say they are afraid of losing face if they speak since they may say something stupid. outstanding students usually say they fear being looked upon as showoffs by their classmates (also creating 
loss of face) if they speak too often or say things that are obviously brilliant (p.120).

\section{U.S. Students}

However, U.S. students tend to exhibit different behaviors. Students can engage in verbal activities with teachers. Students are learning the skills of analysis and synthesis and are applying those skills to the process of "discovering new knowledge" (Sung, 1979).

U.S. classrooms tend to emphasize individualism and the idea of student as decision maker. They have been trained since very early in their lives to consider themselves as separate individuals who are responsible for their own situations in life and their own destinies (Athen, 1988). They have learned to solve problems, to use the library for research, to analyze information, and to expect certain consequences of their decisions (Sue, 1977). Teachers encourage informal discussions and debates in their classes to develop independent thinking (Stewart, 1991).

\section{Learning}

In the U.S., "prefigurative" learning patterns permit and encourage younger students to inform or even disagree with older teachers. These changes in classrooms in recent years have encouraged more student-centered activities (Sato, 1982). Teachers may consider knowledge more relative or negotiable. Lively class discussions play an important 
role in these types of learning contexts (Meacham, 1970). Questions such as "Do you agree with that?" are intended to evoke classroom interaction and not compliance.

Sato (1982) also notes that it is not enough to quantify classroom interaction in terms of turn taking. One needs to know how students use the time once they do get a turn. In Chinese classrooms, in most cases, no personal opinions are expressed. The interactions consist of corrections of information being put on the blackboard by the teacher, and exchanges related to classroom and course management $(\mathrm{Hu}, 1991)$. Opinions are sometimes expressed during the break when some students gather around the professor. Students don't always accept the professor's opinion blindly. out of respect for the professor, not wanting to embarrass him/her, students might keep their opinions to themselves (Van Naerseen, 1984). In a word, a Chinese approach to education generally means learning a text, learning from lectures, learning the information and applying that knowledge to problems to find solutions.

In contrast, a U.S. approach to education generally means learning how to ask questions, learning how to explore material, learning how to formulate and defend one's own answer. This assumes the possibility of more than one answer but does not preclude the learning of facts as well. In the U.S. classes, there are opinions offered and even joking around (Steward, 1991). Learning is considered not 
just a process of memorizing as much as one can of a more or less fixed body of knowledge that already exists in books and in teachers' minds (Hu, 1991). Learning is an enterprise of exploration, experimentation, analysis, and synthesis (Althen, 1988, p.58).

\section{Teacher/Student Relationships}

The teacher-student relationship is culturally mandated. Perhaps the greatest difference between chinese teachers and U.S. teachers is the quality of the relationships they tend to have with their students. In the U.S., the school system is informal with close social relationships between teachers and students, but this usually means that the two have developed an informal way of interacting in which they view each other less and less in superior-subordinate roles (Steward, 1991). Teachers may wear jeans and T-shirts, drink Coke, use informal language to talk in class, and expect students to ask them questions or even challenge what they say. Teachers do not generally assume that they know all there is to know about a subject. Nor do they assume that they invariably explain things clearly. Some students address teachers by their first. names, eat in class, read newspapers, use informal postures, and readily criticize teachers if they feel the teachers are wrong.

Chinese classrooms provide a contrast to U.S. 
classrooms. Students sit in rows of desks that face the teacher, they rise when a teacher enters the classroom, and they raise their hands when asking or answering questions (sung, 1979). The teacher is in complete control of the classroom (Hu, 1991). Students call their teachers "Teacher Wang", "Teacher Chen" or "Teacher" instead of calling them by the first name. Closeness between teachers and students does not usually involve informality or a lessening of deference and respect on the part of the students. Among the Chinese, respectful formality and polite correctness are not viewed as harmful to a caring relationship ( $\mathrm{Hu}, 1991)$.

\section{DEFINITIONS}

The following definitions are very important for understanding concepts throughout this thesis:

1. haptics: touch behaviors

2. vocalics: vocal sounds

3. teacher-centered education: information presented by the teacher. The teacher corrects, criticizes, or rejects erroneous or irrelevant student contributions (Mckeachie, 1986).

4. student-centered education: much student participation, determined by group (Faw, 1949).

5. learner-centered education: a teacher adapts style to the learning needs of the students (Pia, 1989).

6. laoshi: teacher (translation from Chinese) 


\section{CHAPTER III}

\section{METHODS AND PROCEDURES}

\section{Overview}

The purpose of this study is to examine behavioral differences exhibited by U.S. teachers in the U.S. university classroom and Chinese teachers in the chinese university classroom. This chapter outlines the methods and procedures used to describe, collect, and analyze the data generated by the study. It is divided into four sections. The first section discusses the strengths and limitations of the study. The second section describes subjects in the study. The third section gives an overview of the procedures used in the study. The fourth section describes how the researcher trained an assistant to complete the coding matrix following a priori categories.

\section{Strengths of the study}

A main strength of this study is the absence of subject manipulation; the subjects were video-taped in their classrooms. Additionally, U.S. teachers and Chinese teachers in China are selected as the unit of observation in order to avoid observing Chinese teachers only in the U.S., 
possibly already socialized into American norms.

\section{Limitations of the study}

The main limitation of this study is that it was difficult to supervise the video-taping in China. For political reasons, the researcher could not go to China to do the video-taping herself and she had to depend on someone else to select the Chinese classes for her and complete the video-taping.

The second limitation of the study concerns time restriction and tape restrictions. Due to time restrictions, the researcher could not tape more classes. Normally, more video-tapes might reflect more detail of teacher behaviors.

\section{Subjects}

The subject population in this study is undergraduate university instructors or professors whose ages are under 40 years old in both the U.S. and China. Three male university teachers in the U.S. and three male university teachers in China were observed and video-taped. Same gender and similar ages decrease potential validity problems that may affect data results (Frey, Botan, Frideman \& Kreps, 1992). one Chinese university teacher is an associate professor, and five teachers are university instructors. The three U.S. instructors are graduate students studying in the 
English Department at Portland State University.

\section{Procedures}

Descriptive quantitative and qualitative content analysis were used in this study. According to Morgan (1993), qualitative content analysis is distinctively qualitative in both its approach to coding and its interpretations of counts from codes. Qualitative analysts are much more likely to use the data themselves as the source of their codes and qualitative content analysis frequently involves broader and more subjective code categories than its quantitative cousin. He also states that the strengths of qualitative content analysis is comparative analysis. This study is a comparative analysis of the behavioral differences between U.S. university teachers and Chinese university teachers.

This researcher video-taped selected English classes at Portland State University and a Chinese university instructor video-taped selected Chinese classes at Nanjing Normal University in China, and mailed these video tapes back to the researcher.

First level English in the U.S. (English 101) and first level Chinese in China were video-taped because English and Chinese classes are required in both university systems. Classes were about 45-60 minutes long. Each teacher was video-taped three times. In total, there were eighteen one 
hour tapes, nine from Chinese teachers and nine from the U.S. teachers.

Before conducting any research and video-taping, the researcher received the approved letter from the Human Subjects Committee at Portland State University. Also the researcher and the Chinese instructors received verbal permission from schools and departments in which the teachers work and from the teachers themselves. In the classroom before video-taping, the researcher handed "Informed consent forms to Teachers" and "Informed consent forms to students" to receive the video-tape permission from both teachers and students (See Appendix A).

The researcher used a small portable camcorder, which remained at the back of the classrooms, did not use any extra lighting, and did not disturb or distract teachers and students in the classrooms during the video-taping. The teachers reported the following numbers of students enrolled in each class: 20, 22, and 18 students in three U.S. classes; and 50, 80, and 60 students in three Chinese classes. The researcher video-taped both teachers and students. However, most of video-tape time focused on teachers.

Twenty four minutes of each tape were viewed and analyzed. The twenty four minutes were divided in three eight minutes segments. The first segment was the first 8 minutes of class. The second 8 minutes segment was the 17 th 
to the 25 th minutes of class. The last 8 minutes segment was the final 8 minutes of class. These eight minute segments represent three very different parts of a class hour: the beginning, the middle and the end.

\section{Analysis}

The data analysis replicated Lieberman's (1993) research in which she observed behaviors of classroom teachers from 5 different cultural backgrounds and analyzed the data according to Hofstede's (1986) two-dimensional model of cultural differences. The data in this research were also analyzed according to Gudykunst's (1988) identification of two verbal communication styles. The verbal and nonverbal differences identified in the data were analyzed according to the following a priori categories (See Appendix B, for example of coding categories):

* inquires asked by teachers

* comments made by teachers

* length of time that teachers talked in class

* individualistic behaviors encouraged by teachers

* collectivistic behaviors encouraged by teachers

* small power distance between teachers and students

* large power distance between teachers and students

* direct communication style used by teachers and students

* indirect communication style used by teachers and students

* personal style using by teachers 
* contextual style using by teachers

* setting of chairs

* teacher/student ratio

* teachers' haptic (touch behaviors)

* teacher's eye-contact

These categories had previously been established by Gudykunst (1988), Hofstede (1986), Lieberman (1993) and represented potential indicators of cultural styles. Specific behaviors, as identified by the researchers (Gudykunst, 1988; Hofstede, 1986； Lieberman, 1993), associated with each category are indexed in Appendix C. These identified behaviors guided the data analysis for this research.

The data obtained were content analyzed because content analysis may be used to identify, enumerate, and analyze occurrences of specific messages and message characteristics all embedded primarily in mediated texts (Frey, Botan, Friedman and Kreps, 1992) and reported by percentage. According to Frey (1992), a primary goal of content analysis is to describe characteristics of content of the messages embedded in mediated and public texts. Content analysis is an objective, systematic, and quantitative approach to analyzing tests. This study demonstrates the purposes of a content analysis of communication behavior. The researcher used content categories that had proved effective in previous studies in order to identify the 
behavioral differences between U.S. and Chinese university teachers.

Based upon categories of behavioral indicators of cultural styles by Gudykunst (1988), Hofstede (1986), and Lieberman (1993), the researcher make four same categories (see Appendix C); that is individualist societies/direct communication style; collectivist societies/indirect communication style; small power distance/personal communication style and large power distance/contextual communication style. Each category is also divided into eight small categories. For example, there are eight small categories in individualist societies/direct communication; that is, individual students speak up in class response to a general invitation by the teacher; individuals speak up in large groups; students expect to learn how to learn; subgroupings in class vary from one situation to the next based on universalist criteria; conflicts can be brought into the open; teachers are expected to be strictly impartial; students can question teachers in class; and teachers and students speak their minds freely through direct verbal expressions, honestly and openness. The researcher and the research assistant make line of dashes in each category following by three eight minutes segments, then get the data.

However, to improve the richness of the data, the researcher used a qualitative content analysis approach to 
analyze context, because qualitative content analysis uses coded categories that emerge from the data themselves, applies these codes through careful readings of the data, and treats counting as the detection of patterns to guide the further interpretation of the data (Morgan, 1993). Also the strength of qualitative content analysis is comparative analysis. For example, to compare some nonverbal behaviors differences in the classroom, quantitative content may not show in the content analysis. The qualitative content analysis explicitly answers questions about what differences are present in the data as well as further explanations about why these differences occur.

\section{The power of video}

Video represents an immediate and easily accessible medium for conveying information. Not only are people used to receiving information through this technology, but the medium also has a way of shaping belief systems and values (Stevens, 1993). Stevens (1993) also states that video extends people's experience with human diversity with an immediacy and imagery that a written text cannot achieve. video allows viewers to study how human communication works: how understandings-and misunderstandings-of one another are affected by such factors as appearances, speech styles, postures, and intensity of expression (p. 5). 
Videotapes have proven useful in studying university teachers' behavior in the classroom because the tapes can be played over and over again and it is possible to extract meanings from the situation that might otherwise be missed (Fox, 1984). After receiving all required tapes, the researcher and the trained coder viewed and analyzed each tape for behavioral differences between the Chinese and U.S. teachers.

\section{Training the research assistant}

The researcher and the trained assistant viewed the tapes. The researcher and the assistant can speak both Chinese and English fluently. The researcher came to the U.S. four years ago and Chinese is her first language. The assistant came to the U.S. when he was thirteen years old. Now he is twenty-six years old.

\section{Intercoder reliability}

The researcher trained another individual to code the tapes. In the beginning, the researcher sat down with the assistant to view 10 minutes of the tape together. Then she trained him to record the data he observed on the tape following the categories in the Matrix (see Appendix B). The researcher coded one U.S. tape and the trained assistant separately coded the same tape. Intercoder reliability was 
66\%. The researcher continued training the assistant and they each watched and re-coded. By the end of the second viewing, intercoder reliability was $88 \%$

Before analyzing the data in the tapes, the researcher sat down with the assistant to view 10 minutes of tape together. Then she trained him to record the data he observed on the tape following a priori categories in the Matrix (see Appendix B). The data the trained assistant recorded were compared with the researcher's recordings and checked for reliability. Intercoder reliability was $66 \%$. The ratings were discussed and another 10 minutes of tape were viewed. Intercoder reliability for this viewing was 88\%. Because intercoder reliability was high, the researcher and trained assistant proceeded to follow this method. The data between the two coders was counted and analyzed by viewing all tapes and analyzing the data in the tapes separately and independently. Eighteen one hour tapes totally were viewed and twenty four minutes of each tape were analyzed. The researcher watched nine tapes totally, five Chinese teachers' tapes and four U.S. teachers' tapes. The research assistant watched another nine tapes, four Chinese teachers' tapes and five U.S. teachers' tapes. Both the researcher and the research assistant spent at least one and half hour watching and analyzing each individual tape, that is, totally twenty seven hours for all tapes. 


\section{CHAPTER IV}

\section{RESULTS}

Three male university teachers in U.S. and three male university teachers in China were observed and video-taped in this study. Each class was about 60 minutes long and each teacher was video-taped three times. In total, there were eighteen one hour tapes. The researcher and the research assistant separately viewed and analyzed nine tapes, twenty four minutes of each tape. The twenty four minutes were divided in three eight minutes of class segments. The first segment was the first eight minutes of class. The second eight minutes segment was the seventeenth to the twenty-fifth minutes of class. The last eight minutes segment was the final eight minutes of class.

The data analysis was guided by categories established by Gudykunst (1988), Hofstede (1986), and Lieberman (1993) as behavioral indicators of cultural styles (see Appendix C) and qualitative analyses that were beyond the categories established by previous researchers. 


\section{Overall descriptive observation}

After viewing all eighteen tapes, the researcher and the research assistant recorded the number of the individual behaviors of three male chinese teachers and three male U.S. teachers by observed individualist/direct communication, collectivist/indirect communication style, small power distance/personal style and large power distance/contextual style following the established categories by Gudykunst (1988), Hofstede (1986) and Lieberman (1993) (see Table I and II). Each cell represents the frequency of particular behaviors exhibited by the teacher.

Table I

Individual Observation of Chinese Teachers Behaviors By Individualist/Collectivism and Power Distance

Chinese Teacher 1

Individualist/Direct communication style

Collectivist/Indirect communication style

Small power distance/ Personal style

Large power distance/ Contextual style

$\begin{array}{rrrr}\text { Tape } 1 & \text { Tape } 2 & \text { Tape } 3 & \text { Total } \\ 4 & 4 & 3 & 11 \\ 12 & 10 & 15 & 35 \\ 3 & 2 & 1 & 6 \\ 17 & 16 & 15 & 48\end{array}$




\begin{tabular}{|c|c|c|c|c|}
\hline Chinese Teacher 2 & Tape 1 & Tape 2 & Tape 3 & Total \\
\hline $\begin{array}{l}\text { Individualist/Direct } \\
\text { communication style }\end{array}$ & 4 & 7 & 4 & 15 \\
\hline $\begin{array}{l}\text { Collectivist/Indirect } \\
\text { communication style }\end{array}$ & 26 & 13 & 11 & 50 \\
\hline $\begin{array}{l}\text { Small power distance/ } \\
\text { Personal style }\end{array}$ & 2 & 6 & 3 & 11 \\
\hline $\begin{array}{l}\text { Large power distance/ } \\
\text { Contextual style }\end{array}$ & 17 & 14 & 12 & 43 \\
\hline Chinese Teacher 3 & Tape 1 & Tape 2 & Tape 3 & Total \\
\hline $\begin{array}{l}\text { Individualism/Direct } \\
\text { communication style }\end{array}$ & 0 & 0 & 4 & 4 \\
\hline $\begin{array}{l}\text { Collectivist/Indirect } \\
\text { communication style }\end{array}$ & 10 & 4 & 11 & 25 \\
\hline $\begin{array}{l}\text { Small power distance/ } \\
\text { Personal style }\end{array}$ & 0 & 0 & 3 & 3 \\
\hline $\begin{array}{l}\text { Large power distance/ } \\
\text { Contextual style }\end{array}$ & 15 & 14 & 12 & 40 \\
\hline
\end{tabular}

Table II

Individual observation of U.S. Teachers Behaviors By Individualist/Collectivism and Power Distance

U.S Teacher 1

Individualist/Direct communication style

Collectivist/Indirect communication style

Small power distance/ Personal style

Large power distance/ Contextual style

$\begin{array}{rrrr}\text { Tape } 1 & \text { Tape } 2 & \text { Tape } 3 & \text { Total } \\ 48 & 33 & 63 & 144 \\ 0 & 0 & 0 & 0 \\ 49 & 32 & 44 & 125 \\ 0 & 0 & 0 & 0\end{array}$


U.S Teacher 2

Individualist/Direct

communication style

Collectivist/Indirect communication style

Small power distance/ Personal style

Large power distance/ Contextual style

U.S Teacher 3

Individualist/Direct communication style

Collectivist/Indirect communication style

Small power distance/ Personal style

Large power distance/ Contextual style

$\begin{array}{rrrr}\text { Tape } 1 & \text { Tape } 2 & \text { Tape } 3 & \text { Total } \\ 86 & 54 & 31 & 171 \\ 0 & 0 & 0 & 0 \\ 87 & 49 & 27 & 163 \\ 0 & 0 & 0 & 0\end{array}$

Tape 1 Tape 2 Tape 3 Total

51

48

47

146

0

2

6

8

27

31

30

88

2

1

3

6

The Chinese tapes indicated the greatest number of behaviors encouraged in classes were the collectivist/indirect communication style domain and the large power distance/contextual style domain. The three Chinese teachers exhibited 35,50 and 25 types of collectivist/indirect communication style behaviors, and 48, 43 , and 40 types of behaviors representing the large power distance/contextual style. Interestingly, the U.S. teachers encouraged fewer collectivist/indirect communication style 
and large power distance/contextual style. They encouraged individualist/direct communication style and small power distance/personal style. The number of individualist/direct communication style behaviors exhibited by each of the U.S. teacher totaled 144, 171, and 146 respectively and totaled $125,163,88$ respectively for small power distance/personal style behaviors (see Table I\& II).

A summary of the number of behaviors observed for the Chinese teachers and U.S. teachers behaviors is displayed in Table III. Table III displays the percentage of overall types of behaviors exhibited by teachers by culture.

\section{Table III}

Total Observation of Chinese And U.S. Teachers Behaviors By Individualist/Collectivism and Power Distance

Chinese Teachers U.S. Teacher Total

Individualist/Direct communication style

Collectivist/Indirect communication style

Small power distance/ Personal style

Large power distance/ Contextual style
$30 / 6 \%$

$110 / 93 \%$

$20 / 5 \%$

$131 / 96 \%$
$461 / 94 \%$

491

$8 / 7 \%$

$376 / 95 \%$ 396

$6 / 4 \%$

A significant trend in behavioral differences exhibited in the classroom by Chinese university teachers and U.S. university teachers was found (see Table III). The three 
Chinese teachers exhibited 110 types of collectivist/indirect communication style behaviors which was $93 \%$ of the overall types of collectivist/indirect behaviors exhibited. The number of large power distance/contextual style behaviors exhibited by the three Chinese teachers totaled 131 which was $96 \%$ of the total observed. However, the three U.S. teachers exhibited 461 types of individualist/direct communication style behaviors which $94 \%$ those behaviors observed. 376 types of small power distance/personal style behaviors were exhibited by the three U.S. teachers which was $95 \%$ of these types of behaviors observed. These suggest that U.S. university teachers encouraged their students to exhibit significantly more individualist/direct communication styles and small power distance/personal style, while Chinese university teachers encouraged their students to exhibit significantly more collectivist/indirect communication style and large power distance/contextual style.

\section{Qualitative accounts of observations}

In the U.S. class, U.S. teachers encouraged individualism by giving the topics to let students discuss and answer without calling individual student names. The questions they asked, for example, "Who can recall what the questions were? How and why did you know and think of that? 
Do you agree with that? How many people agree with that? Do others have comments about that? Are there any questions you want to bring up?"... U.S. teachers also encouraged individuals through comments they made. For instance, they like to use the words "OK", "Great" or "That's good thinking." There were many free discussions in class. Individuals spoke up in class spontaneously, asked questions immediately, used the teacher's first name, and seemed to speak their minds freely through direct verbal expressions and openness. For example, students used the word "I" often, such as "I think" "I understand" "I mean." They laughed often when the teacher made a joke, and drank coffee and ate snacks in class. Two of the U.S. teachers wore jeans and T-shirts in class, one wore jeans and a sport shirt. None of them wore suits and ties. They joked around, sat on the table when lecturing, and waited for students to ask them questions or even challenge what they said. For example, they asked: "Does anyone have better ideas than mine? Are there any comments about what I have said?"

The teachers in the U.S. have both the role of guiding students to find answers themselves and the role of teaching students how to ask questions. Sometimes, the teacher might answer, "I don't know" to a question the student had asked and then discuss the question with the students or find the answer after class. Students participated and were 
involved in all activities and tried to discover knowledge by themselves. Also, all three of U.S. teachers encouraged small groups discussions. The class was divided into five or six small groups. Each small group was given the same topics to discuss, chose a leader, and then presented their results in class.

There was a lot of eye-contact between U.S. teachers and students. Students looked at the teachers when they asked or answered questions. The teachers looked at the students when they mentioned a topic, and the students looked at each other when they disagreed or discussed an issue. There were no haptics at all between teachers and students. Each student had an individual chair by themselves, but chairs were not arranged in order. One U.S. teacher let his students sit around him, the other two let their students sit facing them.

However, Chinese teachers encouraged individualism in class by pointing to the students to answer questions. To show the respect to the teacher, the individual who was called by name had to stand up to answer questions the teacher asked, and also all Chinese classes students stood up to greet the teacher when he entered the classroom. Questions which Chinese teachers liked to ask were, for example, "Do you remember what we learned last time? Who can remember well and talk about that? What do you think about this article after I explained it?..." 
In class, students were busy taking notes and listening. Few individuals asked questions, and students spoke up only when invited. The Chinese teachers wrote the outlines and important notes on the blackboard and students copied these and wrote in their books quietly. only one teacher encouraged small group discussions. He divided the whole class into many small groups with four students in each group. He gave the topics for them to discuss, then asked questions to some students about what they discussed in the group and what they thought.

The Chinese teachers wore formal dress in class. One of them wore a suit and a tie. The other two teachers wore typical Chinese Mao suits. Most of time, the Chinese teachers stood in front of the blackboard and lectured. But they drank a cup of tea in class when lecturing. However, no other students had that privilege.

The teachers' table was twice as big as students' desks. All chairs were arranged in rows, two or three students shared one desk and a bench. There was approx 1" between each desk. The teachers' table was in front of the classroom, and all students' desks faced the teacher's.

There was little eye-contact between the Chinese teachers and students. The teachers looked at the students when lecturing or silent waiting, while students looked down at their books and wrote notes all the time. There were no haptics between Chinese teachers and students. 
Chinese teachers pointed to students a lot, but there was no touching at all.

The Matrix (see Appendix B) shows some examples of differences between Chinese and U.S. teachers. Also transcriptions (see Appendix D) gave a little detail description of the differences betwean what Chinese and U.S. teachers said and did for the first and last two minutes in class. 


\section{CHAPTER V}

\section{DISCUSSION}

Cultural differences reflect the differences of people's values and assumptions (Condon \& Youself, 1987). For example, the U.S. culture reflects values, such as individualism, direct communication style, small power distance, and personal communication style. However, Chinese values tend to be grounded in collectivism, indirect communication, large power distance, and contextual communication style (Gudykunst, 1988; Hofstede, 1986;

Lieberman, 1993) This study examines behavioral differences exhibited by U.S. teachers in the U.S. university classroom and Chinese teachers in the Chinese university classroom. Three male university teachers in the U.S. and three male university teachers in China were observed and videotaped in this study. Each class was about 60 minutes long and video-taped three times. In total, there were eighteen one hour tapes. The researcher and the research assistant viewed and analyzed all the tapes. In this chapter, the research results will be discussed in relation to U.S. and Chinese cultural values.

First, overall descriptive observation data were reported. Second, qualitative accounts of observation 
were analyzed. The discussion section addressed why particular U.S. and Chinese university teachers' behavioral differences were exhibited in the classroom.

\section{Results to research questions}

Research Question one: What behaviors do U.S. and Chinese university teachers exhibit that reflect Hofstede's concept of "individualist" and Gudykunst's direct communication style?

Individualist cultures, according to Hofstede (1986), assume that people look for their own interest and pursue individual achievement. Behaviors of people might have a positive association with whatever is new and challenging. In the classroom, in order to encourage individualistic behavior, the teachers gave the topics to let students discuss. To show their individualism, the students spoke up spontaneously and asked questions immediately. The teaching style in class is free discussion, student-centered education. These behaviors are seen clearly in three U.S. university classes.

Direct communication style, according to Gudykunst (1988), refers to verbal messages that embody and invoke speakers' true intentions in terms of their wants, needs, and desires in the discourse process. Emphasis is on selfexpression. In the classroom, both teachers and students, 
could speak their minds freely through direct verbal expressions and openness. The U.S. teachers say, "I don't know" or "I am not sure" many times in class when, in fact, they don't know. The students speak out and express what they think in class even if others laugh at it.

Research Question Two: What behaviors do U.S. and Chinese university teachers exhibit that reflect Hofstede's concept of "collectivist" and Gudykunst's indirect communication style?

Hofstede (1986) states that collectivist cultures assume that any person belongs to one or more tight "ingroup." The "in-group" protects the interest of its members, but in turn, expects their permanent loyalty. Behaviors of people might have a more positive association with that which is rooted in tradition. In the collectivist classroom, the virtues of harmony and the maintenance of "face" reign supreme (Hofstede, 1991). Confrontations and conflicts should be avoided, or at least formulated so as not to hurt anyone; even students should not lose face if this can be avoided. So there were no apparent conflicts between the teachers and students or between students and students. Chinese people have a saying: "Saving other's face by showing every regard for his/her status, needs, and is implicit in protecting your own face."

The value orientation of collectivism is seen by group harmony and conformity. These are accomplished through the 
use of imprecise, ambiguous verbal communication behaviors. To be respectful and considerate of the teacher, there is no questions asked in class. Most of time the teachers lecture, write the outlines on the blackboard; while at the same time, the students listen, take notes in their book, and try to remember the teachers' lectures.

Research Question Three: What behaviors do U.S. and Chinese university teachers exhibit that reflect Hofstede's concept of "small power distance" and Gudykunst's personal communication style?

According to Hofstede (1986), small power distance characterizes a society in which people may be uncomfortable with an unequal distribution of power and thus try to bring about a more nearly equal distribution. In the U.S., teachers tend to respect the independence of their students, using student-centered education, and students are even encouraged to contradict or criticize teachers. To show the equality, the teachers ask their students questions such as "What do you think?" or "What is your comment?." It is also acceptable for the teachers to say "I don't know" to their students. In the small power distance classroom, the students use the teacher's first name, laugh often, joke with the teacher, and sometimes eat and drink.

Personal communication style, according to Gudykunst (1988), is individual-centered language. It refers to the use of certain linguistic devices to enhance the sense of 
"I" identity. For example, in the U.S. classroom, both the teachers and students use the word "I" often as in "I think" "I understand" "I mean."

Research Question Four: What behaviors do U.S. and Chinese university teachers exhibit that reflect Hofstede's concept of "large power distance" and Gudykunst's contextual communication style?

Large power distance, according to Hofstede (1991), characterizes a society in which people may be comfortable with an unequal distribution of power. In Chinese classrooms, teachers tend to merit the respect of their students, using teacher-centered education and teachers are neither contradicted nor publicly criticized. The students have to stand up when the teacher enters and stand up to answer questions if called upon. The teachers outline the intellectual paths to be followed and students learn by Iistening, watching, imitating, and taking notes. The teachers initiate all activities and students in class speak up only when invited. The teachers wear formal clothing because they think they have to set a good example for the students. There are some settings in the classrooms, too. For example, teachers' table is always bigger than students' and faces the students.

Contextual communication style, according to Gudykunst (1988), is role-centered language. Verbal contextual style refers to the use of language to reflect hierarchical social 
order and asymmetrical role positions. In the classroom, both the teachers and students use a lot of the famous writers' opinions to express their own opinions. The students use notes or the teacher's ideas as their own when they answer questions.

\section{Overall descriptive observation and qualitative accounts of observations}

Several interesting findings occurred among overall descriptive observation and qualitative accounts of observations. First, a powerful trend in behavioral differences exhibited in the classroom by U.S. university teachers and Chinese university teachers was found. The findings in this research strongly support findings by Gudykunst (1988), Hofstede (1986), and Lieberman (1993) that behaviors of U.S. university teachers exhibited more individualist/direct communication styles and small power distance/personal communication style than the Chinese teachers, while behaviors of Chinese university teachers exhibited more collectivist/indirect communication style and large power distance/contextual communication style than the U.S. teachers. Second, the results of this research provide valuable insights for both U.S. university teachers and Chinese university teachers; that is, culture reflects teachers' and students' values and assumptions (Condon \& 
Yousef, 1987). U. S. culture reflects values, such as individualism, direct communication style, small power distance, and personal communication style. However, Chinese culture reflects collectivism, indirect communication style, large power distance and contextual communication style.

How can these findings relate to cultural values? What people are taught in their culture is different from what others are taught in other cultures. As people grow up, they learn certain values and assumptions from their parents, relatives, teachers, books, newspapers, and television programs. For example, people raised in the U.S. tend to assume that education requires learners to question and challenge the older "expert" when the expert's ideas disagree with the learners' (Althen, 1988). While in China, people assume that education takes place most efficiently when respectful young people absorb all they can of what older, wiser people already know. The young people tend not to challenge nor to discuss what they are taught (Liu, $1984)$.

Though this research uses in a reliability small sample size, the individual subjects observed tend to exhibit behaviors that reflect their own cultures. The behavioral differences of teachers and students in the U.S. and China are, in part, linked to the Confucian tradition. Confucian orthodoxy places a high value on education, particularly on 
educating the members of society in the ways humans should relate to each other. It stresses the benefits of fixed hierarchical relationships, and the confucian relationship between the teacher and student is much more hierarchical than teacher and student relationships in the U.S. (Nelson \& Brown, 1995) Confucian education emphasized "a uniform teaching method, teacher-centric preferences, passive learning modes," and unquestioning students (Robinson, 1991, p. 13). Within the Confucian tradition, the teacher is an authority figure and must know all (Hudson-Ross \& Dong, 1990). Teachers are knowers and carriers of knowledge and they pass that knowledge on to their students. In general, teachers do not admit that they do not know something, and students do not ask questions that would lead to such a statement.

The lack of student questioning in Chinese classrooms relates to "face saving". Hu states (1991) that "poor Chinese students usually say they are afraid of losing face if they speak since they may say something stupid. Outstanding students usually say they fear being looked upon as showoffs by their classmates (also creating loss of face) if they speak too often or say things that are obviously brilliant." students do not ask questions in class, because they do not want the teacher to lose face; they do not want to put the teacher in the position of not knowing something (Hu, 1991). Chinese are more sensitive about losing face 
than Americans (Hofstede, 1991). Also Chinese students will feel uncomfortable in expressing their views in public. If they have questions in class, students will use time outside of class to ask the teacher (Hu, 1991).

The researcher thinks that another reason why students don't ask questions in class is because they are taught and trained that way. Teacher in Chinese is translated as "laoshi". "Lao" means "old and wisdom". "Shi" means the person who teaches and passes on specific skills. In China, the role of a "laoshi" is said to be "jiaoshu yuren", which is translated "to teach book and to educate people." Even more extensive, the "laoshi" role overlaps that of the student's parents. Students have to respect teachers and follow what teachers want them to do. In class, students are taught and trained to be good listeners. Being a good listener is considered good manners among the Chinese. Young Chinese show humility and good upbringing to their elders and teachers by listening much and speaking little.

One interesting thing is that the researcher and the research assistant found out that there were differences between word "respect" in the U.S. and in China. The U.S. students show their respect to the teachers by greeting teachers in class, using special tone and some respectful words talking with teachers, using eye contact all the time, calling the teacher by first name, eating and drinking in 
class. However, Chinese students show their respect by standing up to answer any questions, using "laoshi" instead of calling the teachers' first names and listening to the lecture in class without asking questions.

Two other issues need to be addressed. First, in the U.S., most first level (English 101) university classes are taught by graduate students. However, in Chinese universities, the first level Chinese classes are taught by either the instructors or associate professors. Though all teachers ages in this study are under 40 , there are still differences. Second, the numbers of students in classroom are greatly different. In each U.S. class, the numbers of students enrolled were 20,22 , and 18 ; while in each Chinese class, the numbers were 50,80 , and 60 .

Interestingly, society is changing and behaviors of the U.S. and Chinese teachers in class are changing, too. Now U.S. university teachers try to use some of collectivist teaching methods and the contextual communication style in their teachings and in their class. For example, they might use group discussion and group presentations. These help students to be concerned about others and to work as a team. All of the U.S. teachers video-taped in this study used this method in their class. It is the same with Chinese teachers. One of the three Chinese university teachers (Chinese teacher 2) is trying to change his teaching method into student-center education. To let more 
students participate in class, he divided his class into a few groups. Each group discussed the same topics. Then the leader of each group presented to the whole class. Students could speak up in class when they wanted to and could ask questions when they had not understood something. Every student in class was involved in discussions in the groups. However, only a few students spoke up. The other two Chinese teachers did not seem to change the traditional Chinese teaching methods; that is, they lectured the whole class, wrote the outlines on the board, and pointed to the students to answer questions.

Based upon the existing intercultural differences in the field and the results of this study, this researcher suggests the following for Chinese teachers teaching U.S. students and U.S. teachers teaching Chinese students.

\section{Chinese teachers}

1. U.S. students might feel comfortable calling a teacher by first name instead of calling by title.

2. U.S. students might eat and drink in class.

3. U.S. students might question, criticize and speak direct to the instructor in class.

4. U.S. students might say "No" directly to the instructor.

5. U.S. students might feel uncomfortable if they are treated differently.

6. U.S. students might joke back if the instructor makes a 
joke to them in class.

7. U.S. students might feel comfortable in expressing their views and opinions in class.

8. U.S. students might use a lot of eye-contact to the instructor in class.

9. U.S. students might feel uncomfortable if the instructor touches to them.

10. U.S. students might feel uncomfortable if they are asked to stand up to answer questions.

\section{U.S. teachers}

1. Chinese students might feel uncomfortable to be called by their first name.

2. Chinese students might feel uncomfortable eating and drinking in class.

3. Chinese students might feel uncomfortable if their work is criticized in front of fellow students.

4. Chinese students might feel uncomfortable disagreeing with the instructor.

5. Chinese students might accept being treated differently.

6. Chinese students might feel uncomfortable if a joke is made that requires them to joke back.

7. Chinese students might feel uncomfortable in expressing their views and opinions in class.

8. Chinese students might feel uncomfortable using a lot of eye-contact in class. 
9. Chinese students might feel uncomfortable if touched in class.

10. Chinese students might stand up to answer questions during class.

\section{Limitations}

There are several limitations in the present study. Two limitations were noticed before the researcher did this research. First, it was difficult for the researcher to supervise the video-taping in China. For political reasons, the researcher could not go to China to do the video-taping herself and she had to depend on someone else to select the Chinese classes for her and complete the video-taping.

The second limitation of the study concerns time restrictions and tape restrictions. The researcher received a total of eighteen one hour tapes, nine of them were the three U.S. university teachers and nine of them were the Chinese university teachers. The researcher watched nine tapes, four of the U.S. teachers' tapes and five of the Chinese teachers' tapes. The research assistant watched nine tapes, five of the U.S. teachers and four of the Chinese teachers. Normally, more video-tapes might reflect more details of the teacher behaviors.

The third limitation of the study is the personality of each individual teacher. The out-going teachers joke a 
lot in class and more students get involved and participate. This affects behavioral differences in class, too. For example, two U.S. teachers and one Chinese teacher have outgoing personalities. The number of behaviors exhibited in classes by these teachers are different in the number from behaviors exhibited by other teachers of the same culture who are not as out-going.

The fourth limitation of the study involves the video taping techniques. Because both the researcher and the video-tape recorder in China are not professionals, some parts of video-tapes were affected by noise and it was hard to hear clearly for the researcher and the research assistant.

The language barrier is another limitation in this study. Although the researcher and the researcher assistant speak English fluently, they still have some problems understanding every single sentence and every single joke the U.S. teachers made in class.

\section{Recommendations for future study}

There are four suggestions for future research in this area. First, the U.S. university teachers in this research are the white males under 40 years old. Because most teachers at this university are caucasian, it was difficult to find under represented cultures in the sample. The 
future studies should consider including minority teachers in the U.S. Perhaps their behaviors in the classroom are different than the white male teachers' behaviors in the classroom.

Second, the researcher did not video tape female university teachers in the U.S. classroom and Chinese classroom. $\mathrm{Hu}$ (1991) states that the female teachers normally lecture longer in class than the male teachers and teaching methods differ between female teachers and male teachers. If behaviors of female university teachers in the U.S. and China are different from male behaviors, this should be examined. Both the U.S. and Chinese university teachers, regardless of gender, will benefit from the results of these studies and increase their awareness of culture sensitivity in the classroom.

Third, age is another suggestion for future study. Different age people reflect different behaviors, especially in China, because wisdom comes with age. It will be very interesting to study and find the results that different age teachers exhibit different behaviors in U.S. and Chinese university classrooms.

Another suggestion for future research might consider that would be to rely upon both a chinese researcher and U.S. research assistant or U.S. researcher and Chinese research assistant. This would avoid potential coding because it is less potential coding bias. 


\section{Conclusion}

It is apparent that cross-cultural research addressing problem-solving approaches encouraged by teachers of different cultures is an area of study that invites further research. This research provides an initial link between pedagogical literature and intercultural communication literature. More in-depth research in this area is welcomed and benefit instructors and students in this ever increasing global village. 


\section{REFERENCES}

Althen, Gary (1988). American ways - a guide for foreigners in the United States. Intercultural press, Inc. Yarmouth, Maine

Andersen, Jamos F. \& Powell Robert (1991). Intercultural Communication and the Classroom ( 6 th ed.). Basic Principles of Intercultural Communication, 5-22 Wadsworth

Austin, D. Swanson \& Zhang, Zhian (1987). Education reform in China. Phi Delta Kappan 370-375

Becker, Julie (1983). A cross-cultural comparison of interaction patterns in the classroom. Master's thesis, San Diego State University Publishing Company 208-214 Bellah, R.,

Civikly, J.M. (1986). Communicating in college classrooms. The ethnocentric classroom Jossey-Bass Inc., Publishers, San Francisco Condon, John C. (1986).

Condon, John C. \& Yousef Fathi S. (1987). An introduction to intercultural communication. Macmillan Publishing Company, New York

Corwin, Stephen J. (1978). Classroom Communication in a Very Foreign Land. Theory into Practice 17 (5) $416-420$

Dowrick, Peter W. (1991). Practical Guide to Using Video in the Behavioral sciences. A Wiley-Interscience Publication, John Wiley \& Sons, Inc. New York

Fox, Sharon E. \& Platt, Nancy G. (1984). Using videotapes for illustrations of writing research findings. Eric ED 252876

Frey, R. L., Botan, C. H.; Friedman P. G. \& Kreps, G. I. (1992). Interpreting communication research New Jersey: Prentice-Hall

Gudykunst, William B, Kim (1991). Communication with strangers (2nd ed.). New York: Random House

Gudykunst, William B. \& Nishida, Tsukasa (1986). Attributional confidence in low- and high-context cultures. Human communication research 12 (4) 525549 
Gudykunst, William B., Ting-Toomey, Stella \& Chua E. (1988). Verbal communication styles. Culture and interpersonal communication Newbury Park: Sage Pub.

Hall, Edward T. (1969). The Hidden Dimensions. Garden City, N.Y. Anchor Books

Hayhoe, Ruth and Bastid, Marianne (1987). China's education and the industrialized world: studies in cultural

transfer. M. E. Sharpe, Inc. Armonk, New York/London

Heider, F (1958). The psychology of Interpersonal

Relations. New York: John Wiley

Hofstede, Geert (1980). Cultural's consequences:

International differences in work related values. Newbury Park, CA: Sage

Hofstede, Geert (1986). Cultural Differences In Teaching and Learning International Journal of International Relations, 10, 301-320

Hofstede, Geert (1991). Cultures and organizations: Software of the mind. London: McGraw-Hill

Hu, Wenzhong \& Grove, Cornelius L. (1991). Encountering the Chinese. Intercultural Press, Inc

Hudson-Ross, S \& Dong, Y.R. (1990). Literacy learning as a reflection of language and culture: Chinese elementary school education. The Reading Teacher, 44, 110-123

Hui, C. H. \& Triandis, H. C. (1986). Individualismcollectivism: A study of cross-cultural researchers. Journal of Cross-cultural Psychology, 17, 225-248

Hsu, Francis L. K. (1981). Americans \& Chinese: Passage to differences. The University Press of Hawaii, Honolulu

Kelley, H. (1972). Attribution in social interaction. In E. Johns, K. Kanouse, H. Kelley, R. Nisbett, S. Valins, \& B. Weiner (Eds.), Attribution: Perceiving the Cases of Behavior, 1-26, Morristown, NJ: General Learning Press.

Liang, Qiu Lu (1991). Communication stressors and coping strategies among Chinese Students in the United States Master's thesis, Portland State University

Liebermann, Devorah A. (1991). Intercultural Communication: A Reader ( 7 th ed.). Ethnocognitivism, problem solving, and hemisphericity 178-193 Wadsworth, Inc. 
Liu, Zongren (1984). Two years in the melting pot. San Francisco: China Books \& Periodicals

Lu, Lina (1991). A qualitative case study of Chinese teaching assistant' ' communication in the U.S. university classroom Master's thesis, Portland State University

Mackerras, Colin \& Yorke, Amanda (1991). The Cambridge Handbook of Contemporary China. Cambridge University Press

Madsen, R., Sullivan, W., \& Tipton, S. (1985). Habits of the heart: Individualism and commitment in American life. New York: Harper \& Row

Meacham, Merle L. \& Wiesen Allen E. (1970). Changing Classroom Behavior. International Textbook Company Scranton, Pennsylvania

Morgan, David L. (1993). Qualitiative Content Analysis: A Guide To Paths Not Taken. Qualitative Health Research, Vol. 3 No. 1, February 1993, 112-121

Nelson, Gayle L. \& Brown, Kimberley (1994). Hofstede's Four-Dimensional Model of Cultural Differences: Pedagogical Applications

okabe, $\mathrm{K}$ (1983). Indirect speech acts of the Japanese. In D.L. Kincaid (Ed.), Communication theory: Eastern and Western perspectives (pp.127-136). New York: Academic Press

Pia, Alex (1989). Preferred perceptual learning styles of Chinese students. Master's theis, Portland state University

Robinson, J.H. (1991). Linguistic, cultural and educational contexts of Korea (Working Paper \#10. The Korea Papers: Profiles in Educational Exchange). Washington, D.C.: National Association of Foreign Student Affairs: Association of International Educations.

Sato, C. (1982). Ethnic styles in classroom discourse on TESOL 1981 (eds M. Hines and $W$. Rutherford.) Washington, D.C: TESOL

Starck, Kenneth (1991). The dragon's pupils-- a China odyssey. Iowa State University Press, Ames, Iowa 50010

Stevens, Gregory I. (1993). Videos for understanding diversity: A core selection and evaluative guide. 
American Library Association, Chicago and London

Stewart, Edward C. \& Bennett, Milton J. (1991). American cultural patterns - a cross-cultural perspective (Revised edition). Intercultural Press, Inc. Yarmouth, Maine

Sung, Betty Lee (1979). Transplanted Chinese Children. Eric ED 182040

Tebeau, sue (1977). Cultural Factors. A Guide to Understanding Asian ESL Students Eric

Teper, Shirley (1977). Ethnicity, Race and Human

Development New York: Institute on Pluralism and Group Identity of the American Jewish Committee

Thomas, D Snyder (1992). Digest of education statistics 1992 U.S. department of education office of educational research and improvement NCES 92-097

The Chinese Education Association for International Exchanges (1987). The China Higher Education Directory Hon Wing Book Co. Ltd

Van Naerseen, M., Huang, N.E., \& Yarnall E. (1984). How Is a Chinese Student Like a Thermos Bottle? Eric ED $\underline{249818}$

Yum, June Ock (1988). The Impact of Confucianism on Interpersonal Relationships and Communication Patterns in East Asia Communication Monographs, Volume 55 , December $1988,378-388$

Waterman, A. S. (1981). Individualism and interdependence. American Psychologist, $36,762-773$.

Zhu, Wei (1991). A Chinese teacher's efforts to promote cross-cultural communication Eric ED 343139

Zikopoulos, Marianthi (1993). Open doors -- 1992-1993. Report on international educational exchange. Institute of International Education, 809 United Nations Plaza, New York, NY 10017-3580 
APPENDIX A

INFORMED CONSENT FORM FOR TEACHERS AND STUDENTS 


\section{INFORMED CONSENT FORM FOR TEACHERS}

I, , agree to take part in this research project on comparing behavioral differences in the classroom: American university teachers and Chinese university teachers.

I understand that the study involves video-taping me and the class.

I understand that, because of this study, I may be uncomfortable and inconvenient facing the cameras in class. Xiaocheih Sun has told me that the purpose of the study is to identify potential culture differences between U.S. university teachers and Chinese university teachers.

I may not receive any direct benefit from taking part in this study. But the study may help to increase knowledge that may help others in the future.

Xiaocheih Sun has offered to answer any questions I have about the study and what I am expected to do.

She has promised that all information I give will be kept confidential to the extent permitted by law, and that the names of all people in the study will remain confidential.

I understand that I may withdraw from this study without affecting my course or my relationship with Portland State University. 
I have read and understand the above information and agree to take part in this study.

Date:

Signature:

If you have concerns or questions about this study, please contact the Chair of the Human Subjects Research Review Committee, Office of Research \& Sponsored Projects, 105 Neuberger Hall, Portland State University, 503/725-3417. 


\section{INFORMED CONSENT FORM FOR STUDENTS}

I, , agree to take part in this research project on comparing behavioral differences in the classroom: American university teachers and Chinese university teachers.

I understand that the study involves video-taping the teacher and the class, including me.

I understand that, because of this study, I may be uncomfortable and inconvenient facing the cameras in class. Xiaocheih sun has told me that the purpose of the study is to identify potential culture differences between U.S. university teachers and Chinese university teachers.

I may not receive any direct benefit from taking part in this study. But the study may help to increase knowledge that may help others in the future.

Xiaocheih Sun has offered to answer any questions I have about the study and what I am expected to do. She has promised that all information will be kept confidential to the extent permitted by law, and that the names of all people in the study will remain confidential.

I understand that I may withdraw from this study without affecting my course or my relationship with the teacher and Portland State University and without being 
penalized.

I have read and understand the above information and agree to take part in this study.

Date:

Signature:

If you have concerns or questions about this study, please contact the Chair of the Human Subjects Research Review Committee, office of Research \& Sponsored Projects, 105 Neuberger Hall, Portland State University, 503/725-3417. 


\section{APPENDIX B}

MATRIX 


\begin{tabular}{|c|c|}
\hline & CHINESE TEACHERS \\
\hline & \\
\hline \multirow[t]{6}{*}{ inquires asked by the teacher } & 1. Do you remember what we learned last time? \\
\hline & 2. Who can remember well and talk about that? \\
\hline & 3. What do you think about the article after I explained it ? \\
\hline & 4. What do you think about his answer and how do you feel after he read the article? \\
\hline & 5. What and how do you know that? \\
\hline & 6. How do you evaluate the article? \\
\hline \multirow[t]{4}{*}{ comments made by the teacher } & no verbal response after the students answered or may only say "sit down" \\
\hline & repeat the student's answer and not say "right" or "wrong" \\
\hline & you can't remember it well \\
\hline & correct the answer immediately or repeat the correct answers \\
\hline $\begin{array}{l}\text { length of time talking by the } \\
\text { teacher }\end{array}$ & 60 minutes class and the teacher lectured about 45 minutes \\
\hline \multirow[t]{2}{*}{$\begin{array}{l}\text { individualism encouraged by the } \\
\text { teacher }\end{array}$} & the teacher pointed to the student to answer questions \\
\hline & the teacher gave questions to the students and let them think in a few minutes \\
\hline \multirow[t]{2}{*}{$\begin{array}{l}\text { Collectivism encouraged by the } \\
\text { teacher }\end{array}$} & the students did not ask any questions in class \\
\hline & the teacher asked the simple and easy questions to let the whole class answer together \\
\hline \multirow{3}{*}{ small power distance } & the students repeated the notes together with the teacher \\
\hline & the students laughing in class when the teacher made a joke \\
\hline & the students spoke out the correct answer together if they knew with the teacher \\
\hline \multirow[t]{4}{*}{ large power distance } & all students stood up to greet the teacher when he entered \\
\hline & the student stood up to answer the questions if being called \\
\hline & the student in class spoke up only when invited to \\
\hline & no questions asked by the students \\
\hline
\end{tabular}




\begin{tabular}{|c|c|}
\hline & \\
\hline \multirow[t]{3}{*}{ direct communication style } & the teacher looked at his notes and explained \\
\hline & the teacher gave the outline of the paragraph \\
\hline & the teacher told the story to support his idea \\
\hline \multirow[t]{3}{*}{ indirect communication style } & the students took notes on their book \\
\hline & the students listen, no questions \\
\hline & the teacher wrote the outlines and important notes on the board \\
\hline \multirow[t]{2}{*}{$\begin{array}{l}\text { personal style using by the } \\
\text { teacher }\end{array}$} & the teacher pointed to the students to let them answer questions \\
\hline & the teacher liked to use "l" in class, for example, "I told you..." "I explained it..." \\
\hline $\begin{array}{l}\text { contextual style using by the } \\
\text { teacher }\end{array}$ & the teacher liked to use "because," "as," and "so" to replace whole clause \\
\hline \multicolumn{2}{|l|}{. } \\
\hline \multirow{3}{*}{ setting of chairs } & longer one. \\
\hline & approx. 1" between each desk, the teacher's table in front of the classroom, \\
\hline & student desks face to the teacher's \\
\hline ratio & 58 students \\
\hline \multirow[t]{3}{*}{ haptics } & the teacher stood approx. $0.5^{\prime \prime}$ between the students when he walked towards them, \\
\hline & pointed to the student's book when asked questions, \\
\hline & or looked at the student's book, but no touch to the student \\
\hline \multirow[t]{6}{*}{ eye-contact } & the teacher looked at students when lecturing or silent waiting \\
\hline & the students looked down at the book and wrote notes \\
\hline & $\therefore$ \\
\hline & \\
\hline & \\
\hline & \\
\hline
\end{tabular}




\begin{tabular}{|c|c|}
\hline & U.S. TEACHERS \\
\hline \multirow[t]{8}{*}{ inquires asked by the teacher } & 1. How many people feel stress about the class? \\
\hline & 2. Is there any people wanting to read their journal? \\
\hline & 3. Who can recall for me what the questions were? \\
\hline & 4. Does anyone not understand? \\
\hline & 5. How and why did you know about that? \\
\hline & 6. Does others have comments about that? \\
\hline & 7. How many people feel much better than before after we discussed about that? \\
\hline & 8. Is any questions you want to mention about? \\
\hline \multirow[t]{2}{*}{ comments made by the teacher } & "OK", "Right" or "Good" \\
\hline & That is fine. He brought something... \\
\hline $\begin{array}{l}\text { length of time talking by the } \\
\text { teacher }\end{array}$ & 55 minutes class and the teacher discussed and lectured about 35 minutes \\
\hline \multirow[t]{2}{*}{$\begin{array}{l}\text { individualism encouraged by the } \\
\text { teacher }\end{array}$} & asked the student reading their writing in class \\
\hline & discussed questions and topics without being called the names \\
\hline \multirow[t]{3}{*}{$\begin{array}{l}\text { collectivism encouraged by the } \\
\text { teacher }\end{array}$} & group discussions \\
\hline & each student talked his/her opinions and the teacher wrote them on the board \\
\hline & combined all opinions \\
\hline \multirow[t]{6}{*}{ small power distance } & free discussions \\
\hline & the students asked questions immediately \\
\hline & class \\
\hline & used the teacher's first name to ask questions \\
\hline & laughed about the teacher's writing \\
\hline & the students drank coffee and ate snack bars in class \\
\hline large power distance & the teacher's table is bigger than students' \\
\hline
\end{tabular}




\begin{tabular}{|c|c|}
\hline & the teacher's table is surround by the students chairs \\
\hline \multirow[t]{4}{*}{ direct communication style } & read the book and writings \\
\hline & discussed the writings \\
\hline & explained what they thought and why they thought frankly \\
\hline & asked questions immediately \\
\hline \multirow[t]{2}{*}{ indirect communication style } & the teacher wrote the opinions of the students on the board \\
\hline & no correct the answers immediately \\
\hline \multirow[t]{3}{*}{$\begin{array}{l}\text { personal style using by the } \\
\text { teacher }\end{array}$} & the teacher liked to be called the first name \\
\hline & the teacher encouraged the students to talk jokes in class \\
\hline & the teacher sat on the table \\
\hline \multirow[t]{2}{*}{$\begin{array}{l}\text { contextual style using by the } \\
\text { teacher }\end{array}$} & the teacher liked to use the word "We", for example, "we discussed that..." \\
\hline & the teacher liked to use the sentences "in conclusion", or "to begin with"... \\
\hline setting of chairs & each student has his/her own chair, and did not arrange in order, \\
\hline ratio & 18 students \\
\hline haptics & no touch between the teacher and the students \\
\hline \multirow[t]{9}{*}{ eye-contact } & questions \\
\hline & the teacher looked at the students when he mentioned a topic \\
\hline & the students looked at each other when they discussed questions \\
\hline & \\
\hline & \\
\hline & \\
\hline & . \\
\hline & \\
\hline & \\
\hline
\end{tabular}


APPENDIX C

BEHAVIORAL INDICATORS OF CULTURAL STYLES

(HOFSTEDE, GUDYKUNST, AND LIEBERMAN) 


\begin{tabular}{|c|c|c|c|c|}
\hline & $\begin{array}{l}\text { BEHAVIORAL INDICATORS OF CULTURAL STYLES BY HOFSTEDE, } \\
\text { GUDYKUNST, UEBERMAN }\end{array}$ & $8 \mathrm{~min}$ & $8 \mathrm{~min}$ & $8 \mathrm{~min}$ \\
\hline INDIVIDUALIST SOCIETIES/ & 1. individual students speak up in class in response to a & & & \\
\hline \multirow{10}{*}{ DIRECT COMMUNICATION STYLE } & 2. individuals speak up in large groups & & & \\
\hline & 3. students expect to learn how to learn* & & & \\
\hline & eg. the teacher gave the topics to discuss and asked questions as & & & \\
\hline & based on Universalist criteria (e.g. the task "at hand") & & & \\
\hline & 5. conflicts can be brought into the open & & & \\
\hline & eg. if someone didn't agree with others, he would bring out to argue & & & \\
\hline & in class & & & \\
\hline & 6. teachers are expected to be strictly impartial & & & \\
\hline & eg. the teacher asked questions to the whole class, not only & & & \\
\hline & some particular students & & & \\
\hline COLLECTIVIST SOCIETIES/ & 1. individual students only speak up in class when called & & & \\
\hline \multirow[t]{13}{*}{ INDIRECT COMMUNICATION STYLE } & upon personally by the teacher & & & \\
\hline & 2. individuals only speak up in small groups & & & \\
\hline & 3. students expect to learn how to complete tasks ${ }^{*}$ & & & \\
\hline & eg. the teacher gave all the answerș and asked questions as & & & \\
\hline & "Do you remember what we learned?" & & & \\
\hline & 4. large classes split socially into smaller, cohesive & & & \\
\hline & subgroups based on particulars criteria (e.g. ethnic affiliation) & & & \\
\hline & 5. formal harmony in learning situations should be maintained & & & \\
\hline & at all times (eg. the teacher gave the lecture in class, and students & $\therefore$ & & \\
\hline & took notes all the time quietly) & & & \\
\hline & 6. teachers gave preferential treatment to some students & & & \\
\hline & eg. the teacher called names to ask questions in class & & & \\
\hline & 7. students don't question teachers in class & & & \\
\hline
\end{tabular}




\begin{tabular}{|c|c|c|c|c|}
\hline & $\begin{array}{l}\text { BEHAVIORAL INDICATORS OF CULTURAL STYLES BY HOFSTEDE, } \\
\text { GUDYKUNST, LEBERMAN }\end{array}$ & $8 \mathrm{~min}$ & $8 \mathrm{~min}$ & $8 \mathrm{~min}$ \\
\hline & 8. group harmony and conformity are accomplished through the & & & \\
\hline & use of imprecise, ambiguous verbal communication behaviors & & & \\
\hline SMALL POWER DISTANCE I & 1. teachers respect the independence of his/her students* & & & \\
\hline \multirow[t]{13}{*}{ PERSONAL STYLE } & eg. the teacher liked to ask questions as "What do you think?" & & & \\
\hline & 2. student-centered education (premium on initiative) ${ }^{*}$ & & & \\
\hline & eg. much student participation, determined by the group & & & \\
\hline & 3. teacher expects students to initiate communication* & & & \\
\hline & eg. discussion and asking questions in class & & & \\
\hline & 4. teacher expects students to find their own paths ${ }^{*}$ & & & \\
\hline & eg. students learned by actively doing things and discovering & & & \\
\hline & things by themselves & & & \\
\hline & 5. students may speak up spontaneously in class & & & \\
\hline & 6. students allow to contradict or criticize teachers & & & \\
\hline & 7. verbal personal style is individual-centered language & & & \\
\hline & 8. a person-oriented language stresses informality and & & & \\
\hline & symmetrical power relationships & & & \\
\hline & & & & \\
\hline LARGE POWER DISTANCE/ & 1. teachers merit the respect of his/her students* & & & \\
\hline \multirow[t]{12}{*}{ CONTEXTUAL STYLE } & 2. teacher-centered education (premium on order) ${ }^{*}$ & & & \\
\hline & eg. information presented by the teacher, less student participation & & & \\
\hline & 3. students expect teacher to initiate communication ${ }^{*}$ & & & \\
\hline & eg. the teacher initiated all activities and dealed with various topics & & & \\
\hline & 4. students expect teacher to outline paths to follow* & & & \\
\hline & eg. the teacher gave the answers, students learned by listening, & & & \\
\hline & watching and imitating & & & \\
\hline & 5. students speak up in class only when invited by the teacher & & & \\
\hline & 6. teacher is neither contradicted nor publicly criticized & & & \\
\hline & 7. verbal contextual style is role-centered language & 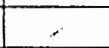 & & \\
\hline & 8. a contextual-oriented language emphasizes formality and & & & \\
\hline & asymmetrical power relationships & & & \\
\hline & & & & \\
\hline
\end{tabular}


APPENDIX D

TRANSCRIPTS 
Chinese 1 Class - First 2 minutes of class

Student: "Stand up."

Teacher: "Sit down. Last time, we talked about Chao Yuanming's article. He is one of the greatest writer in Qing's Dynasty. We knew some of him already. What do you know and think about him? You, (pointed to one of student) talk briefly about him what you have learned."

Student: (stood up) "I knew two points about Chao Yuanming in last class. First, Chao loved nature. Second, he didn't like the city life and society, so he moved to countryside."

Teacher: "You talked a little bit. You can't remember well. I will ask another one to answer." (He walked to one student) What did you learn?"

Student: (stood up, and silent for 20 seconds)

Teacher: "Sit down. All of you have to review what we learned last class. Otherwise you can't study well and reach my points. Now we review again together what we learned last time. This poet was born in Qing Dynasty and we have to know that specific time. When he was 42 , he resigned and moved to countryside. He is the first poet to write about countryside, nature, earth. He loves nature, and hates politics..."

Chinese 1 Class - Last 2 minutes of class

Teacher: "We have finished this whole article. I will give you some homework to do. First, you need to review what we learned today and organize the important points. Second, turn to page 65. There are three questions on this page. I only want you to do the first question. Hand it to me at the next class. Class is over." 
U.S. 1 Class - First 2 minutes of class

Teacher: "Let me have your papers, please." (He went to each of the students to get their papers. One student tried to explain something.) "OK. If you don't have a paper, see me after class." (He came to another student) "Did you get your haircut?"

"So difficult, easy, painful, pleasurable. How many people feel they can get right into the paper? (students raised their hands) How many people thought it is more stressful? (students raised their hands again) Does anyone want to read their journal entry? (no one answered, only heard some laughing)

\section{U.S. 1 Class - Last 2 minutes of class}

Teacher: "Why don't we do these for Thursday? We are behind. We haven't yet done Gardner's and Fencher's essays. Peruse those two essays once more. We will discuss more on Thursday. When I have you to do your journal entry in class, let's have it on the subject content, not personal. I will give you some text oriented questions. Try to stick with the subject and see how it goes. The other thing is that I will try to hand these back to you next Thursday with comment on it. It is just check, check minus, and check plus. All right. I will see you next Thursday. Have a great day and weekend!" 
Chinese 2 Class - First 2 minutes of class

Teacher: "Be quiet, please. We will start our class now. stop talking. We know from the articles we have learned before that there is a patten in our literature history, that is many famous modern writers are also good at history. For example, Lu Xun, one of the greatest modern writers, studied a lot in our history..."

Chinese 2 Class - Last 2 minutes of class

Teacher: "OK. We have only discussed and learned the first part of the article. We will continue to study and discuss the last part of the article in next class. Class is over. Goodbye."

Student: "Stand up." 
U.S. 2 Class - First 2 minutes of class

Teacher: "Well. Today we will talk about the topics and thesis, and how to use both of them. Also we will talk a little bit about sentences. But first of all, I would like to ask you to try to get involving as far as the second half of term. What I want you to do maybe look through the Reader and think about which readings may be interesting to you. Has anyone looked through the Reader at all?"

U.S. 2 Class - Last 2 minutes of class

Teacher: We didn't get to the topics yet. I think it is important and we will get it next time. Is there any questions? (One student comes up and talks with him. Others leave.) 
Chinese 3 Class - First 2 minutes of class

Student: Stand up.

Teacher: Sit down.

Teacher: I believer there are many students here like to read novels. Is that true? It is saying that a good novel can let people forget eating and sleeping. We don't want to put it away before finishing reading it. After finishing the book, we will remember what the characters said and expressed. It will mark in our mind. Why does it give us a deep impression? This is what we study today...

Chinese 3 Class - Last 2 minutes of class

Teacher: I think we have to stop here. After class, you need to do some homework. Today you need to write a short paper to describe a person's character using what we learned before. Class is over. Goodbye.

Student: Stand up. Goodbye. 


\section{U.S. 3 Class - First 2 minutes of class}

Teacher: The week of syllabus is changing. I don't think I don't need to make up the whole new one for the week of July 26 to July 29. Is that clear? I made the error.

Student: Is this an assume that we will have it until then? Teacher: Yes. We will definite have it by then. Now discuss which one of topics that your group picked up and write it on the paper...

\section{U.S. 3 Class - Last 2 minutes of class}

Teacher: OK. We don't have time to go on because we have work to do. At the end of class, would you please put the desks back to the rows. I will be appreciated. On Monday, keep on reading journals, working on essays.

Student: Not on Monday. It is on Tuesday.

Teacher: Right. I won't be here on Monday. On Tuesday, we will start the journal essays from page 300 on schedule. Write it fun. Have a good weekend. I am here to help you if you need anything in another 30 minutes. 